Mini review

\title{
Recent Developments in Electrochemical, Electrochemiluminescent, Photoelectrochemical Methods for the Detection of Caspase-3 Activity
}

\author{
Changdong Chen and Ming $L a^{*}$ \\ College of Chemistry and Chemical Engineering, Pingdingshan University, Pingdingshan, Henan \\ 467000, People's Republic of China \\ *E-mail: mingla2011@163.com
}

doi: $10.20964 / 2020.07 .58$

Received: 26 February 2020 / Accepted: 28 April 2020 / Published: 10 June 2020

Caspase-3 plays an important role in the apoptotic process and has drawn fast growing interests in cancer research, clinical detection and apoptosis-targeted drug discovery. Increasing demands for simple, low-cost and high-performance clinical diagnosis have already promoted the rapid progress in analysis of caspase-3. During plenty of novel methods for caspase-3 determination, electrochemistrybased methods, have been worldly recognized as the most promising technologies because of their simplicity, high sensitivity and specificity. This review aims to briefly summary the recent developments of electrochemical, electrochemiluminescent, photoelectrochemical methods, and provide insights into the incorporation of electroactive molecules or nanomaterials.

Keywords: caspase-3; electrochemistry; electrochemiluminescence; photoelectrochemistry; signal amplification

\section{FULL TEXT}

(C) 2020 The Authors. Published by ESG (www.electrochemsci.org). This article is an open access article distributed under the terms and conditions of the Creative Commons Attribution license (http://creativecommons.org/licenses/by/4.0/). 